\title{
Study of the Operation of Solar Modules Using Holographic Thermal Protection
}

\author{
Irina Kirpichnikova ${ }^{1,}$ Ilkhom Makhsumov ${ }^{1, *}$, Zhenis Madiyar ${ }^{1}$, Ilkhom Abdulloev $^{1}$, Khurshedshoh Boboev ${ }^{1}$ and Parviz \\ Shohnazarov ${ }^{1}$
}

${ }^{1}$ National Research South Ural State University, Polytechnic Institute, 454080 Chelyabinsk, Russia

\begin{abstract}
This paper explores the problem of overheating of solar modules as a result of exposure to sunlight. An increase in temperature above the standard leads to the degradation of solar modules and their premature decommissioning. Cooling the working surface is a key factor that must be considered in order to achieve higher efficiency in the operation of solar photovoltaic systems. Based on the considered methods of cooling and removing excess heat from the surfaces of the modules, an inexpensive and technologically advanced method for protecting solar modules from overheating using holographic films was proposed. The article presents the results of comparative laboratory tests of solar modules using such a holographic thermal protection. It is shown that when using a film, the SM performance does not change, and in some cases even gets better. The surface temperature of the module depends on the angle of its inclination to the horizon, which must be taken into account when choosing the location of installation of solar power plants. The experiments confirmed the assumption of effective protection of the modules from overheating using holographic thermal protection and showed its promise.
\end{abstract}

\section{Introduction}

One of the most common renewable energy production technologies is the use of photovoltaic (PV) systems that convert sunlight into usable electrical energy [1-2]. This type of technology for the use of renewable energy sources that do not contain pollutants during operation reduces global warming problems, reduces operating costs and offers minimal maintenance and the highest specific power compared to other renewable energy technologies [3-4].

In addition to the advantages demonstrated by photovoltaic technology, this conversion system has some common problems, such as hail, dust, and the working surface temperature, which can negatively affect the efficiency of solar modules and power plants in general [5]. Exogenous climatic parameters, such as wind speed, ambient temperature, relative humidity, accumulated dust and solar radiation, are the most common natural factors that affect the surface temperature of a photovoltaic module [6]. Each increase in the surface temperature of the PV module by $1{ }^{\circ} \mathrm{C}$ compared to the standard temperature of $25^{\circ} \mathrm{C}$ leads to a decrease in the efficiency by $0.5 \%$ [7]. Therefore, due to a rise in temperature, not all solar energy absorbed by photovoltaic cells is converted into electrical energy. To satisfy the law of conservation of energy, the remaining solar energy is converted into heat. The consequences of this lost heat lead to a decrease in the overall conversion efficiency. In order for the technology of using renewable energy sources to be a viable solution, it is necessary to find various ways to solve this temperature problem, which should lead to an increase in the overall conversion efficiency. Many researchers have dealt with the search for various methods and technologies for reducing the surface temperature of solar modules. Thus, the authors of the article cited in [8] analyzed various cooling technologies for solar photovoltaic panels. It was shown that only a few technologies were introduced from the methods considered. In [9], the main attention was paid to the consideration of methods of passive, forced air and liquid convection cooling used in various systems of solar concentrators. All the methods discussed above, as a rule, use complex devices to cool or remove heat from the surface of the modules. In our opinion, the problem of reducing the overheating of modules must be solved simultaneously with the solution of the problem increase their productivity. This issue is especially relevant for areas with electricity shortages and high solar insolation.

\section{Description of the operation of the solar photovoltaic system}

When the photocell is exposed to solar radiation, the photon is absorbed by the $\mathrm{P}-\mathrm{N}$ junction, which $\mathrm{c}$ currentvoltage reates a potential difference at the junction. In the circuit parallel to the P-N junction diode, the resulting IPV photocurrent begins to flow [10]. This can be seen on the equivalent photocell circuit (Fig. 1).

\footnotetext{
* Corresponding author: messi.ilhom@ gmail.com
} 


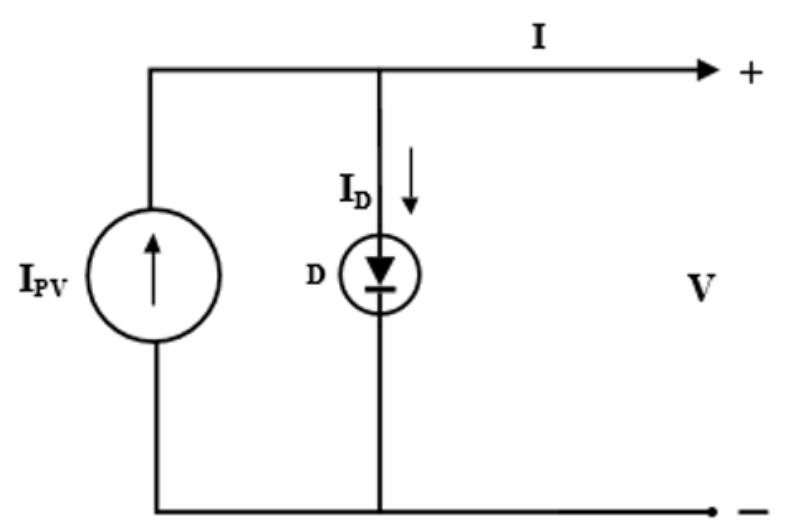

Fig. 1. The equivalent circuit of the photocell [11].

A study of the performance of the solar cell shows that the surface temperature plays a decisive role in the process of converting photoelectric energy. High ambient temperatures and high operating temperatures of the PV panel surface cause it to overheat, which affects the current-voltage characteristic and radically reduces the efficiency of the device [12]. The preferred operating temperature of the solar modules is in the range of $0{ }^{\circ} \mathrm{C}$ to $75^{\circ} \mathrm{C}$. The characteristics of the modules are the ratio between the output power and the output voltage, while the solar illumination $\mathrm{E}$ and the temperature of the module $\mathrm{T}_{\mathrm{m}}$ are kept constant. The effect of temperature on the electrical efficiency of solar panels can be analyzed using the following equation:

$$
\eta_{P V}=\eta_{T R}\left[1-\beta_{R}\left(T_{C}-T_{R}\right)+\gamma \log _{10} I_{P V}\right]
$$

where: $\eta_{P V}-$ is the efficiency of the photovoltaic module, measured at the temperature of the reference cell; $T_{R}(25$ $\left.{ }^{\circ} \mathrm{C}\right), \quad \beta_{R}-$ is the temperature coefficient for cell efficiency (typically $0.004-0.005 /{ }^{\circ} \mathrm{C}$ ) $[13] ; I_{P V}$ - average hourly radiation incident on the photovoltaic module at rated operating temperature; $T_{C}-$ is the temperature of the photovoltaic module, but $r-$ is the radiation intensity coefficient for the cell efficiency, which is basically assumed to be zero [14-15], reducing the equation to:

$$
\eta_{P V}=\eta_{T R}\left[1-\beta_{R}\left(T_{C}-T_{R}\right)\right]
$$

It follows that the higher the surface temperature of the module, the lower its efficiency.

\section{Hybrid solar PV/thermal (PV/T) cooled by forced water circulation}

In order to increase the efficiency of photovoltaic systems The authors of [16] proposed a hybrid photovoltaic thermal (PV/T) system, which generates electrical and thermal energy simultaneously. The system consists of a photovoltaic module and heat collector pipes that are attached to the rear of the photovoltaic module. Rectangular sewers are used to improve the contact between the PV unit and the thermal sewers. Water is used as a circulating fluid that flows through parallel heat pipes through a direct current pump that can be powered by a photovoltaic module or other sources. When the hybrid system is exposed to solar radiation, the waste heat is transferred to the circulating water flowing through the heat collector pipes. Heated water is returned to the hot water tank for domestic or other uses. Figure 2 shows this thermoelectric photocell cooling system.

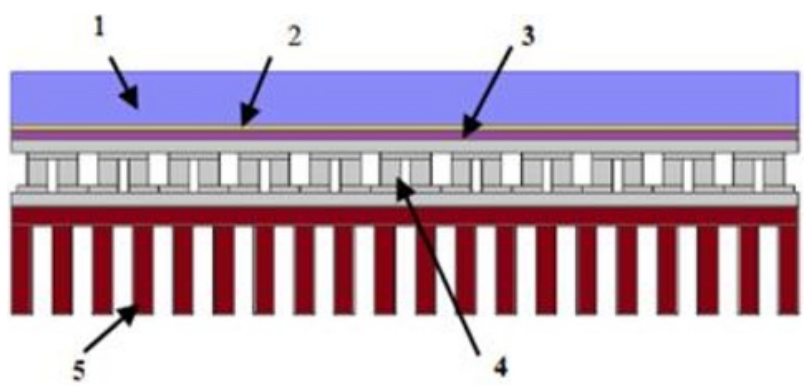

Fig. 2. Thermoelectric cooling system for solar cells [17]. 1 Glass cover; 2 - Photocells; 3 - Water storage tank; 4 - TEG module; 5 - Fin radiator.

This option of heat removal from solar modules, like many others, is bulky and complex in design.

Holographic films. To protect solar modules from overheating at elevated temperatures, we proposed the use of holographic films. Such films are now widely used in the construction of buildings and car interiors from the penetration of infrared (thermal) rays. The main purpose of the films is to protect the premises from overheating in the summer and heat preservation in the winter, which is very important when solving energy conservation issues. A variety of types and types of holographic films make it possible to turn ordinary glass into an element that meets the requirements of safety and comfort. We believe that holographic films can become an effective and economic means of protecting solar modules from high temperature, and, as a result, increase their life without compromising the efficiency of the modules. The specific features of holographic films as a means of preventing overheating will serve the further technological development of solar energy, and the low cost of modules with such thermal protection will accelerate the transition to renewable energy sources.

\section{Description of the experiment in the laboratory}

On the basis of the educational and research laboratory of the South Ural State University, experimental studies of the heating of the surface of solar modules (SM) were carried out at various illumination values. During the experiment, instruments and equipment were used, the characteristics of which are given in table 1 .

Table 1. The list of instruments and equipment used in the experiment

\begin{tabular}{|c|l|l|}
\hline № & \multicolumn{1}{|c|}{ Name of devices } & \multicolumn{1}{c|}{$\begin{array}{c}\text { Technical } \\
\text { parameters }\end{array}$} \\
\hline 1 & Solar module located on & $\begin{array}{l}\text { Mains voltage } 220 \mathrm{~V} \\
\text { Frequency } 50 \mathrm{~Hz}\end{array}$ \\
\hline
\end{tabular}




\begin{tabular}{|c|l|l|}
\hline 2 & $\begin{array}{l}\text { the platform: Temperature } \\
\text { sensor; Light sensor; } \\
\text { Artificial light source. }\end{array}$ & $\begin{array}{l}\text { Power Consumption } \\
350 \mathrm{~W}\end{array}$ \\
\hline 2 & $\begin{array}{l}\text { Management and control } \\
\text { module. Including: } \\
\text { - battery; } \\
\text { - battery charge controller; } \\
\text { - dimmer; } \\
\text { - variable load; } \\
\text { - digital voltmeter; } \\
\text { - digital ammeters (3 pcs); } \\
\text { - digital indicator of } \\
\text { temperature of solar } \\
\text { modules; } \\
\text { - digital indicator of the } \\
\text { energy illuminance of the } \\
\text { solar module (radiometer). }\end{array}$ & $\begin{array}{l}\text { Mains voltage } 220 \mathrm{~V} \\
\text { Poweq Consumption } \\
350 \mathrm{~W}\end{array}$ \\
\hline 3 & $\begin{array}{l}\text { Infrared thermometer } \\
\text { (pyrometer) }\end{array}$ & $\begin{array}{l}\text { Temperature range } 60 \\
{ }^{\circ} \mathrm{C} . . .+1000{ }^{\circ} \mathrm{C}\end{array}$ \\
\hline 4 & \begin{tabular}{l} 
Holographic film \\
\hline
\end{tabular} & - \\
\hline
\end{tabular}

A general view of the experimental stand is shown in Fig. 3.

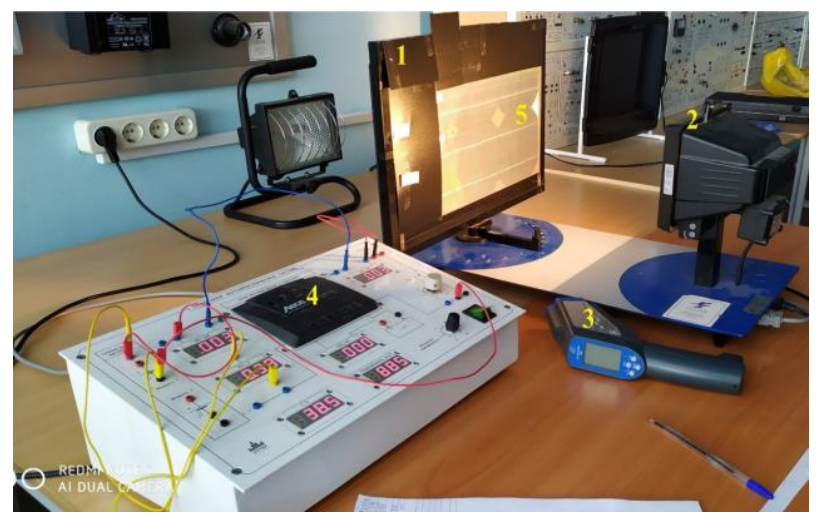

Fig. 3. General view of the experimental stand: $1-5$ - Solar module with a film; 2 - Source of artificial lighting; 3 Infrared thermometer; 4 - Control and monitoring module.

The purpose of the experiment is to investigate the use of a holographic film as a protection for solar modules from overheating. It is known that any shading of the solar module leads to a decrease in the efficiency of its operation. We assumed that a transparent holographic film having an inhomogeneous internal structure will reflect the infrared component of the spectrum, thereby reducing the module overheating and at the same time not lead to a deterioration in its energy characteristics. Comparative tests of solar modules with an open surface and with the surface on which the film is glued were carried out. The following dependencies were determined for such modules:

- heating temperature from the illumination of the surface of the solar module;

- module power from its illumination;

- the power of the module from its angle to the horizon.

The illumination of the surface of the solar module was regulated by the power of an artificial light source in the range from 63 to $1990 \mathrm{~W} / \mathrm{m}^{2}$. The module tilt angle was set from 0 to 90 degrees with respect to direct light beams. The experiments were carried out alternately with the open and closed film surfaces of the solar module.

The results of the study of the dependence of the module power on illumination are presented in table 2 and in figure 4.

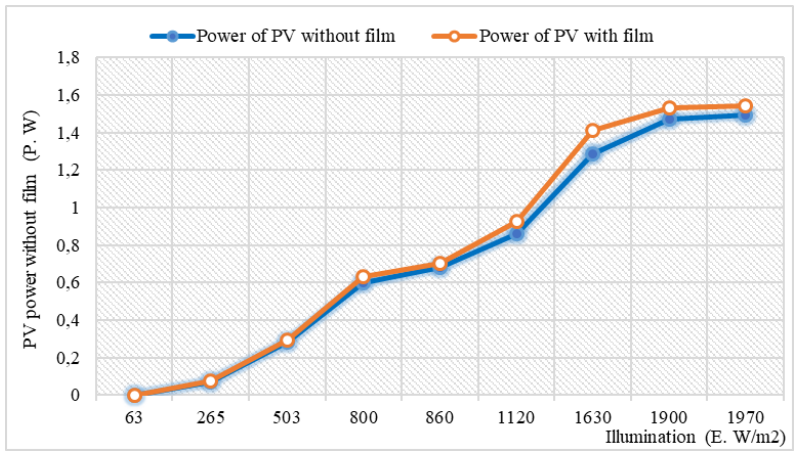

Fig. 4. The dependence of the power of the solar module on the illumination with and without a holographic film.

The graph shows that in low light conditions (up to $860 \mathrm{~W} / \mathrm{m}^{2}$ ), the power of the module does not change, however, with increasing illumination, the difference in power between the open and glued surfaces becomes obvious. Despite the fact that this difference is of little importance, this suggests that the presence of a film does not adversely affect the power of the module, and in some cases (with increased illumination) even leads to its increase.

In table 3 and in fig. 5. dependences of the power of the photovoltaic module on its angle are presented.

The dependence shows that in the range of angles from 10 to 70 degrees, the power of a module with a film is on average 0.15 Watt more than the power of a module with an open surface. The study of the dependence of the surface temperature of the module on illumination showed that the holographic film used has the property of reflecting the infrared component of the electromagnetic spectrum, i.e., prevents the solar module from overheating. Table 4 and Fig. 6 show the obtained values of the heating temperature of the front and rear

Table 2. The dependence of the power of the PV from the illumination.

\begin{tabular}{|c|c|c|c|c|c|}
\hline $\mathrm{E}, \mathrm{W} / \mathrm{m}^{2}$ & $\mathrm{P}_{\text {(with film), } \mathrm{W}}$ & $\mathrm{P}_{\text {(without film), } \mathrm{W}}$ & $\mathrm{E}, \mathrm{W} / \mathrm{m}^{2}$ & $\mathrm{P}_{\text {(with film), } \mathrm{W}}$ & $\mathrm{P}_{\text {(without film), }} \mathrm{W}$ \\
\hline 63 & 0.00171 & 0.00162 & 1120 & 0.9282 & 0.8625 \\
\hline 256 & 0.07436 & 0.0715 & 1630 & 1.4112 & 1.288 \\
\hline 503 & 0.29348 & 0.27993 & 1900 & 1.53 & 1.47 \\
\hline 860 & 0.7004 & 0.6834 & 1970 & 1.54 & 1.4949 \\
\hline
\end{tabular}


Table 3. The dependence of the power of the SM (PV) without film on the angle of inclination.

\begin{tabular}{|c|c|c|c|c|c|}
\hline Tilt angle, $\left(\beta^{\circ}\right)$ & 0 & 10 & 20 & 30 & 40 \\
\hline $\mathrm{P}_{\text {(with film), }} \mathrm{W}$ & 1.5453 & 1.4504 & 1.188 & 0.8625 & 0.6048 \\
\hline $\mathrm{P}_{\text {(without film), } \mathrm{W}}$ & 1.4798 & 1.4162 & 1.2649 & 0.984 & 0.7314 \\
\hline${\text { Tilt angle, }\left(\beta^{\circ}\right)}^{\circ}$ & 50 & 60 & 70 & 80 & 90 \\
\hline $\mathrm{P}_{\text {(with film), } \mathrm{W}}$ & 0.378 & 0.19635 & 0.10426 & 0.039366 & 0.00425 \\
\hline $\mathrm{P}_{\text {(without film), }} \mathrm{W}$ & 0.51156 & 0.28724 & 0.12292 & 0.0308 & 0.0036 \\
\hline
\end{tabular}

Table 4. The temperature of the front and rear surfaces of the solar module with open and film-glued surfaces from light exposure.

\begin{tabular}{|c|c|c|c|c|c|c|c|c|c|}
\hline $\mathrm{E}, \mathrm{W} / \mathrm{m}^{2}$ & 50 & 115 & 620 & 1327 & 1926 & 1999 & 1999 & 1999 & 1999 \\
\hline $\mathrm{t}_{\text {(wit.f-fro.sur), }}\left({ }^{\circ} \mathrm{C}\right)$ & 33.8 & $\begin{array}{r}33 . \\
7\end{array}$ & 34.3 & 35.0 & 35.8 & 36.6 & 38 & 38.9 & 40.1 \\
\hline $\mathrm{t}_{\text {(wit.f-back.sur), }}\left({ }^{0} \mathrm{C}\right)$ & 27.3 & $\begin{array}{r}27 . \\
3\end{array}$ & 27.3 & 27.7 & 27.9 & 28.1 & 28.2 & 28.4 & 28.6 \\
\hline $\mathrm{t}_{\text {(with.f.fro.sur), }}\left({ }^{\circ} \mathrm{C}\right)$ & 32.2 & $\begin{array}{r}32 . \\
1\end{array}$ & 32.8 & 34.3 & 36 & 37.3 & 38 & 38.5 & 39.1 \\
\hline $\mathrm{t}_{\text {(with.f-back.sur), }}\left({ }^{\circ} \mathrm{C}\right)$ & 29.1 & $\begin{array}{r}29 . \\
3\end{array}$ & 29.1 & 28.9 & 31.9 & 32.2 & 32.1 & 32.1 & 32.1 \\
\hline
\end{tabular}

surfaces of the module with and without film, depending on the illumination.

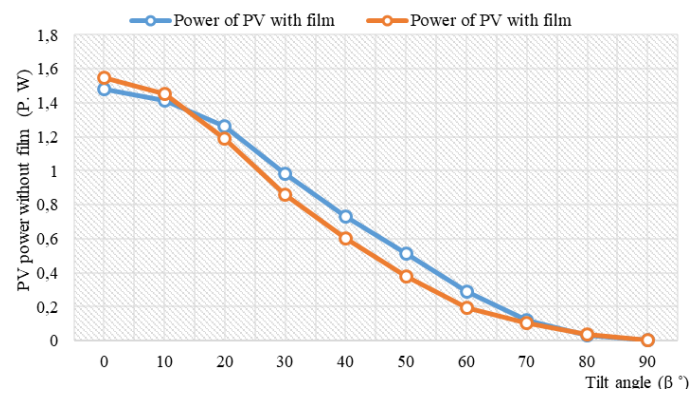

Fig. 5. The dependence of the power of the solar module on the angle of inclination.

As can be seen from the obtained dependences, with an increase in illumination, the surface temperature of a solar module with a film is somewhat lower than with an open surface, but even a slight difference can be the basis for using such films to protect the modules from overheating. The dependence of the heating temperature on the angle of inclination of the solar module, shown in
Fig. 7 shows that the difference in temperature between the two surfaces is more important than when changing illumination.

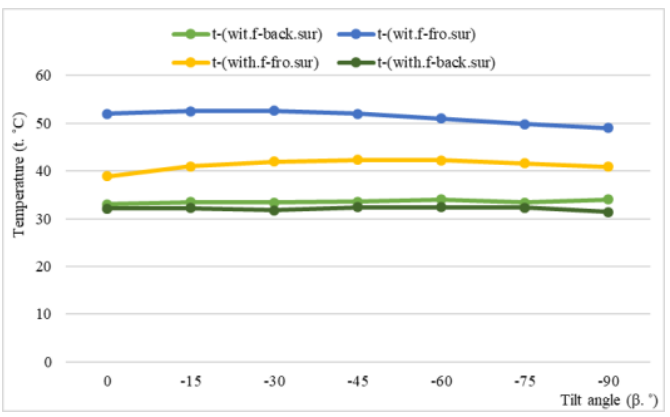

Fig. 7. Temperature dependence on the front and rear surfaces of the solar module with and without film.

The temperatures on the rear surfaces of the modules are almost equal, and on the front surfaces that receive solar radiation, they differ by an average of 10 degrees. This fact suggests the need to take into account the angle of inclination of solar modules when installing them in

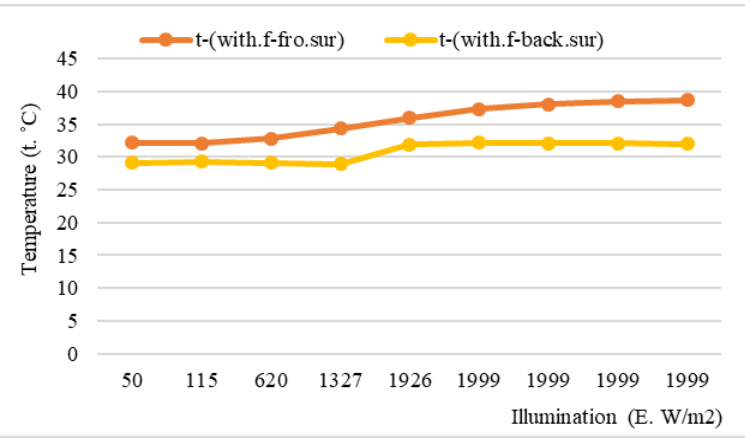

b)

Fig. 6. The dependence of the temperature of the front and rear surfaces of the solar module on the illumination (a) without film and (b) with a holographic film. 
the place of operation.

\section{Conclusions}

1. The performance of solar modules largely depends on the climatic conditions of operation and such parameters as solar radiation, ambient temperature, wind speed, relative humidity, dust, etc.

2. Increased air temperature during the operation of solar modules adversely affects the efficiency of their work.

3. The proposed method for the protection of solar modules allows the use of a low surface temperature of the module without reducing its energy characteristics.

4. The values obtained in laboratory conditions correspond to only one low-power module, however, their revision to a solar power plant, consisting of hundreds and thousands of such modules, can have significant energy and economic effects.

\section{References}

1. J. Hu, W. Chen, D. Yang, B. Zhao, H. Song, B. Ge, Applied Energy, 173 (2016)

2. YH. Yau, KS. Lim, Energy Build, 126 (2016)

3. Y. Wang, S. Zhou, H. Hou, Renewable and Sustainable Energy Reviews, 39 (2014)

4. P. Bhubaneswari, S. Iniyan, R. Goic, Energy Reviews, 15 (2011)

5. RM. da Silva, JLM. Fernandes, Solal Energy, 84 (2010)

6. AM. Elbreki, MA. Alghoul, AN. Al-Shamani et al., Renewable and Sustainable Energy Reviews, 57 (2016)

7. M. W. Davis, A.H. Fanney, B. P. Dougherty, Journal of Solar Energy Engineering, 123 (2001)

8. A. Sahay, VK. Sethi, AC. Tiwari, M. Pandey, Renewable and Sustainable Energy Reviews, 42 (2014)

9. A. Royne, CJ. Dey, DR. Mills, Sol Energy Mater Sol Cells, 86 (2003)

10. J. Siecker, K. Kusakana, B.P. Numbi, Renewable and Sustainable Energy Reviews, 79 (2017)

11. AR. Jordehi, Renewable and Sustainable Energy Reviews, 61 (2016)

12. JA. Duffie, WA. Beckman, Solar engineering of thermal processes, (2013)

13. T. Hove, Renew Energy, 21 (2000)

14. M. Siegel, S. Klein, W. Beckman, Solar Energy, 26 (1981)

15. D. Evans, Solar Energy, 27 (1981)

16. C. Good, Renewable and Sustainable Energy Reviews, 55 (2015)

17. R. Kiflemariam, M. Almas, C. Lin, Proceedings of the COMSOL conference in Boston; (2014)

18. S. N. Litvinov, V. D. Lebedev, N. N. Smirnov, V. V. Tyutikov, I. B. Makhsumov, MATEC Web of Conferences., 194 (2018)

19. E. Raweh1, W. Pi1, O. Busati, A. Rehman, S. Mubbarak, Y. Wang, MATEC Web of Conferences., 107 (2019) 